\title{
Risk Factors that Corroborate for Pregnant Women Admission with Preeclampsia in ICU
}

Ana Paula Agostinho Alencar1, Maria Soléria de Albuquerque',Fernando Luiz Affonso Fonseca1, André Alencar Moreira2 ${ }^{2}$ Mirlla Michelle Alves Uchôa1, Sérgio de Araújo1, George Nilton Nunes Mendes', Hermes Melo Teixeira Batista1, Regina Petrola Bastos Rocha ${ }^{1}$

\section{Abstract}

The Hypertension in pregnancy can be termed syndromes Hypertensive of Gestation, where we have pre-eclampsia as the most serious, which can compromise the life of the pregnant woman and the fetus/ newborn, leading to admission to the Intensive Care Unit for these can receive more specific care and prevent the occurrence of other complications. This study aimed to investigate risk factors that support for the development of pre-eclampsia and its admission to the ICU. This is an integrative literature review study with work resulting from scientific productions, and an exploratory descriptive nature, which is within the qualitative analysis. It was noticed that there is much to be studied and clarified regarding Preeclampsia because the jobs available in the literature showed a deficit of knowledge and shock information about the causes and care where these are often only provided when it is already the most serious stage, and may be a consequence of poor prenatal care. Are remarkable advances that the health system has been presenting in the reduction of maternal and perinatal morbidity and mortality rates, however there is still much to be revised as a way of welcoming and working with this audience, as much see a mechanized service, as the prevention of pre-eclampsia should be accepted by pregnant women as an essential care to be performed during pregnancy.

\section{Introdution}

In high-risk pregnancies Systemic Hypertension (SHT) is among the most frequent causes of maternal mortality. Among the types present in pregnancy include the Chronic Hypertension $(\mathrm{CH})$ and the specific manifestations of pregnancy, which are Specific Hypertension in Preg-
1 Estácio-FMJ

2 UFCA

Contact information:

Hermes Melo Teixeira Batista.

Address: Rua Evangelista Sampaio, 1300. Barbalha/Ce, Brazil.

झ hermesmelo@oi.com.br

\section{Keywords}

Pre-Eclampsia; Risk Factors;

Pregnant Women; UT. 
nancy (SHP) and preeclampsia/eclampsia (PE) that can be clinically defined by the increase of levels of Blood Pressure (BP) after the 20 $0^{\text {th }}$ week of pregnancy, where the values found are equal or above $140 \mathrm{mmHg}$ for systolic pressure and $90 \mathrm{mmHg}$ for diastolic pressure [1].

These three make up the group of Hypertensive Disorders in Pregnancy (HDP), and the Preeclampsia is the aggravation of Chronic Hypertension or Specific of pregnancy, when they are not treated and controlled properly evolves into PE which is the most serious, because it is associated with functional and/ or structural changes in target organs such as the heart, brain, kidneys and blood vessels that affects the system functions of the mother and/or fetus, and may arise from the $20^{\text {th }}$ week of pregnancy indicating interruption of pregnancy [2].

Preeclampsia is characterized by sudden onset or worsening of hypertension accompanied by proteinuria and elevated serum creatinine, uric acid, transaminases levels and generalized edema. It is a hypertensive disorder in pregnancy which leads to reduced blood perfusion in organs and is related to vasospasm, vasoconstriction, metabolic disorders, endothelial dysfunction, activation of the coagulation cascade and autoimmune inflammatory response [3].

The main PE findings are the blood pressure levels above $140 \mathrm{mmHg}$ in systolic blood pressure and $90 \mathrm{mmHg}$ in diastolic, accompanied by proteinuria and the formation of generalized edema, which together form the triad of preeclampsia, though the edema is also very common in gestating that does not progressing to cases of $\mathrm{PE}$, however if it id found is not diagnostic criteria. But when it is observed can be considered the first warning sign, this in a generalized way, especially in the hands and face, always associated with hypertension and proteinuria, the latter is a late manifestation of PE [4].

Diagnosed based on clinical suspicion of the presence of HSP, which during prenatal consultations the BP values are high conforms cited above, which leads to request for evidence through laboratory tests to measure levels of proteinuria greater than 300 mg/24 hrs diagnosed after 20 weeks of gestation to confirm the diagnosis. The seizure occurrence defines a severe form of $P E$, this is called eclampsia. It is important to note that the seizure cannot be attributed to other causes in women with preeclampsia [5].

Studies conducted in some Brazilian maternity hospitals show that fetuses of mothers with PE have higher risks of prematurity, occurrence of small fetuses deliveries for gestational age (SGA), necessity of an intensive care unit (ICU), necessity of ventilatory support and there is a higher incidence of perinatal mortality as compared to normotensive mothers of fetuses [3].

In Eclampsia, seizures are serious complications and can occur during pregnancy, childbirth and the first twelve days of puerperium. It assumes the diagnosis of hypertension and significant proteinuria. The presence of proteinuria should be considered a situation with different risk and hospitalization should prevail regardless of gestational age and especially the presence of signs or symptoms resulting from more severe frames [6].

The evolution of PE is unpredictable, even when the PA is only slightly elevated. Therefore, a failure to recognize it can have serious consequences, leading the progression to eclampsia (seizures) or an intermediate form called imminent eclampsia, which is characterized by severe headache, visual disturbance, hyperreflexia, epigastric pain and hemoconcentration. Sometimes eclamptic seizures occur suddenly, without warning, in apparently asymptomatic patients or with mild high blood pressure [7].

The prevalence of preeclampsia is usually described as 5 to $8 \%$, its values have wide variations in the literature. In twin pregnancy the prevalence of $\mathrm{PE}$ is $14 \%$, since this situation is a risk factor, reaching $40 \%$ in pregnant women with previous PE, being of great relevance the identification the signs 
and symptoms and the health team performance for the prevention of complications [8].

In cases of preeclampsia it is important to identify its severity, because the maternal and fetal prognosis depends on the conduct. Treatment with anti-hypertensive in cases of PE does not alter the pathophysiology of the disease, but may slow its progression and consequently achieve advances in fetal maturation [9].

Women with hypertension in pregnancy are vulnerable and need more attention by the health professionals because they are subject to complications that may require transfer to the Intensive Care Unit (ICU), seeking to mitigate the risks to the mother, fetus/newborn. A good health care to these women include medical and nursing care that depend on accurate diagnosis in order to be executed and evaluated adequately to their needs [10].

According to Amorim et. al. (2006), patients should be referred to an obstetric ICU, where they will receive treatment only for the complications they may develop, since being transferred to a general intensive care unit would not be successfully conducted as in obstetric ICU can offer.

One should be aware of the risk factors that caused pregnant women develop complications as in the case of twin pregnancy, the prevalence of preeclampsia is $14 \%$, reaching $40 \%$. Authors state that the HDP risk factors can be divided into intrinsic or obstetric factors and extrinsic or not obstetric factors [11].

Extrinsic factors are characterized by ethnicity, extremes of maternal age, socioeconomic status, obesity, previous hypertension or renal disorders, whereas the intrinsic or obstetric factors are nulliparity, pregnancies with increased placental mass on uterine distension and ectopic pregnancy [12]. We also have diabetes, personal or family history of preeclampsia and/or chronic hypertension.

Through this research we aimed to investigate risk factors that support for the development of preeclampsia and its admission to ICU.
In this perspective the study aims to describe the complications that cause pregnant women with preeclampsia need to be admitted to ICU. It is important that this group has a quality care, seeking to further reduce the prevalence of morbidity and mortality from this disease which is considered one of the most serious obstetric emergencies. According to Vettore et. al (2011), as a result of the high prevalence of HDP, more studies are being conducted in search of better clarify the risk factors for the development of pathology.

Given the above, some questions that guide the choice for the object of study arise: What is the importance of pregnant women with PE being admitted to ICU? Are there any risk factors pregnant women can develop them? Are pregnant women receiving proper care in the ICU?

The interest in the study came while conducting research for realization of the monograph. We saw the importance of knowing the risk factors that lead to the onset of preeclampsia, which causes very serious risks to pregnant woman/fetus, once knowing them, the complications can be avoided. It is of utmost necessity to deepen the knowledge on this subject, seeking to clarify and build knowledge to provide a more scientific assistance for critical care professionals who serve patients in crisis.

\section{Method}

This is an integrative literature review study with work resulting from scientific productions.

The integrative review includes relevant research analysis that support for decision-making and improve clinical practice, allowing the synthesis of the state of knowledge of a particular subject, while pointing out gaps in knowledge that need to be filled with doing new studies [13].

Mendes p.759, 2008.

Taking into account that electronic databases are updated tools for obtaining knowledge among re- 
searchers, it is possible to opt for it to obtain the data, we used the bibliographical survey in the databases of the Latin American and Caribbean Health Sciences (LILACS), Scientific Electronic Library Online (SciELO), Virtual Health Library (VHL), among others. It was used as keywords: Preeclampsia; Risk factors; pregnant women; ICU.

The study is exploratory and descriptive nature, which is within the qualitative analysis, when for some reason there is a need to collect data and interpret the information gathered in it. [14].

According to Leopardi (2002), exploratory research allows the researcher to expand his experiences on a topic, as well as new information, in turn facilitating the data collection of possible research problems [15].

The option of working with literature review is for the greater amount of information available in the virtual libraries. With the parameters used it was found 46 articles, and after reading the references listed, only those published in English language journals were selected. The materials were carefuIly analyzed for the categorization of subject areas, where besides the titles; the content was analyzed, since the title is not always indicative of the scope of work.

After this analysis 27 references were selected, where the selection of the material was made by keywords, and consideration with relevant title to the subject researched, the rest were discarded for not having the desired content, the publications were limited between 2002 and 2013. The professional category and the authors' area of operation were not taken into account.

\section{Results and Discussions}

After a pre-analysis of 52 references obtained, 25 publications were excluded for not offering content that fit the purpose to which the article sought to explore. As a result of this search, 27 publications were obtained on preeclampsia, between journal articles, master and doctoral theses. It was possible to conclude that the causes for the development of this condition have not been clarified; however, studies bring risk factors that facilitate PE understanding and care.

From the analysis of the obtained publications on the subject, three categories emerged: Socioeconomic profile of pregnant women with preeclampsia; Risk factors that cause a pregnant woman to develop PE; Nursing care provided to pregnant women with $P E$.

\section{Socioeconomic profile of pregnant women with preeclampsia}

It is important to evaluate and describe in detail each factor the socioeconomic profile of pregnant women with preeclampsia has and which confirms the onset and complications of this specific hypertensive syndrome of pregnancy that can lead to complications that expose the mother and fetus death.

Regarding the age of prevalence of $\mathrm{PE}$, it is considered that among the many factors that increase the risk of developing the syndrome, the extreme of age is one of the most aggravating. The chart below shows that the majority of women are in the age under 21 years, whereas Assis, Viana and Rassi (2008) states that pregnant women older than 30 years should also be monitored and forwarded to a prenatal high risk, however, an age limit for maternal and fetal risks elevate has not been established yet [3].

The SBC (2010) emphasizes that hypertension can affect women considered normotensive at any age, it occurs because of exposure to special situations which by itself contribute to the development of hypertension, such as oral contraceptive use, pregnancy and menopause itself [5].

Since the ideal childbearing age is between 20 and 30 years, this fact is because the woman is born with a certain number of eggs, so every month an egg is stimulated by actions of hormones which acts in ovarian follicle to become dominant and prepare to be fertilized and when unfertilized it is elimina- 
ted in menstruation. This happens from the first menstruation (menarche) to the last (menopause), and each month the number of eggs decreases [16].

As for the profession/occupation, evidences show that there is a higher incidence (78\%) when the mother is present in situations like professional activity outside the home, which confirms that there are several factors for the onset of HDP. This factor can be directly related to stress and effort in which the pregnant woman is often submitted, and the rest is one of the best ways to avoid more serious complications [17].

Regarding the level of education, Gonçalves Fernandes and Sobral (2005) reported that low educational level is one of the aggravating factors hindering women's access to information and knowledge on PE, which impairs the conditions for self-care, as it implies both at ease in finding as to assimilate the information received about the mother's health care and the fetus [4]. Table 1

Table 1. Distribution of the number of pregnant women hospitalized with preeclampsia ( $\mathrm{n}$ $=40$ ) according to age and socioeconomic factors. Fortaleza, 2006.

\begin{tabular}{|l|c|c|}
\hline \multicolumn{1}{|c|}{ Variables } & N & $\%$ \\
\hline Maternal age & & \\
\hline $15-21$ & 19 & 47.5 \\
\hline $22-28$ & 09 & 22.5 \\
\hline $29-35$ & 05 & 12.5 \\
\hline $36-43$ & 07 & 17.5 \\
\hline Education (years of schooling) & & \\
\hline 3-7 & 15 & 37.5 \\
\hline 8-13 & 20 & 50 \\
\hline 14-18 & 05 & 12.5 \\
\hline Occupation & & \\
\hline Work at home & 24 & 60 \\
\hline Work out & 16 & 40 \\
\hline Family income (in minimum wages) & & \\
\hline 1-2 & 30 & 75 \\
\hline 3-4 & 5 & 12.5 \\
\hline 5-6 & 5 & 12.5 \\
\hline
\end{tabular}

Source: Moura et al., 2010
As for the profession/occupation, evidence also show that there is a higher incidence, this factor can be directly related to stress and effort in which the pregnant woman is often submitted, and the rest is one of the best ways to avoid more serious complications as well as the care of the evolution and development of pregnancy [17].

With Hypertensive Disorders, maternal mortality rates in Brazil are still considered high, and PE is one of the main causes of this event [18]. So it is considered one of the most important complications of pregnancy/childbirth, with an incidence of $6 \%$ to $30 \%$ of pregnant women and results in a high risk of morbidity and maternal and perinatal mortality [3].

\section{Risk factors that lead a pregnant woman developing preeclampsia}

Sampaio et. al (2013), in their systematic review on risk factors that predispose a pregnant woman to develop PE shows that such features as kidney disease, metabolic disorders such as diabetes and obesity, as well as some of the pregnant characteristics and pregnancy which are Nulliparity, multiple pregnancy, the age group above 30 years, personal or family history of PE and/or chronic hypertension and ethnicity, these factors may contribute to increased the risk of developing it [19].

$\mathrm{SAH}$ in a woman at childbearing age becomes more worrying, since she gets pregnant it may be accompanied by various complications, as the hypertensive disorders are the medical complications of major importance during the pregnancy-puerperal time [20].

Previous studies show that specific hypertensive disorders of pregnancy is present from implantation of the egg and is characterized clinically by an increase in blood pressure after the $20^{\text {th }}$ week of gestation, associated (preeclampsia) or not (HEG) to proteinuria. Before 20 weeks the disease is asymptomatic, depending on its diagnosis only physical examination and laboratory data of the pregnant woman [1]. 
Table 2. Distribution of pregnant women with hypertensive disorders. according to proteinuria. clinical and maternal outcomes.

\begin{tabular}{|c|c|c|c|c|c|c|c|c|c|}
\hline \multirow{2}{*}{ Proteinuria } & \multicolumn{2}{|c|}{ Absent } & \multicolumn{2}{|c|}{$0.3-1.0$} & \multicolumn{2}{|c|}{$1.0-\mid 2.0$} & \multicolumn{2}{|c|}{$\mathbf{2 . 0}$ or more } & \multirow{2}{*}{ p } \\
\hline & \multicolumn{2}{|c|}{ n 203(I) } & \multicolumn{2}{|c|}{ n 39 (II) } & \multicolumn{2}{|c|}{ n 45 (III) } & \multicolumn{2}{|c|}{ n 47 (IV) } & \\
\hline Age & \multicolumn{2}{|c|}{$29.7 \pm$} & \multicolumn{2}{|c|}{$24.5 \pm^{*}$} & \multicolumn{2}{|c|}{$28.8 \pm$} & \multicolumn{2}{|c|}{$28.4 \pm$} & $<0.0001$ \\
\hline \multicolumn{2}{|l|}{ Parity } & \multicolumn{2}{|l|}{$\%$} & \multicolumn{2}{|l|}{$\%$} & \multicolumn{2}{|l|}{$\%$} & $\%$ & \\
\hline Nulliparous & 60 & 29.5 & 24 & 61.5 & 27 & 60.1 & 23 & 48.8 & $<0.0001$ \\
\hline Multiparous & 91 & 44.8 & 12 & 30.7 & 12 & 26.4 & 18 & 38.4 & ns \\
\hline G.Multiparous & 52 & 25.7 & 03 & 7.8 & 06 & 13.5 & 06 & 12.8 & ns \\
\hline \multicolumn{2}{|l|}{ Race } & \multicolumn{2}{|l|}{$\%$} & \multicolumn{2}{|l|}{$\%$} & \multicolumn{2}{|l|}{$\%$} & $\%$ & \\
\hline White & 123 & 60.6 & 24 & 61.5 & 27 & 60.2 & 24 & 51.2 & ns \\
\hline Black & 42 & 20.7 & 09 & 23.2 & 11 & 24.2 & 12 & 25.6 & ns \\
\hline Mulatto & 38 & 18.7 & 06 & 15.3 & 07 & 15.6 & 11 & 23.2 & ns \\
\hline \multicolumn{2}{|l|}{ Type of delivery } & \multicolumn{2}{|l|}{$\%$} & \multicolumn{2}{|l|}{$\%$} & \multicolumn{2}{|l|}{$\%$} & $\%$ & \\
\hline Vaginal & 88 & 43.5 & 07 & 18.0 & 16 & 35.5 & 12 & 25.5 & ns \\
\hline Cesarean & 115 & 56.5 & 32 & $82.0 *$ & 29 & $75.5^{\star}$ & 35 & $74.5^{*}$ & $<0.001$ \\
\hline \multicolumn{2}{|c|}{ Indications of Cesarean delivery } & \multicolumn{2}{|l|}{$\%$} & \multicolumn{2}{|l|}{$\%$} & \multicolumn{2}{|l|}{$\%$} & $\%$ & \\
\hline Maternal & 07 & 6.8 & 06 & $18.7 *$ & 10 & $34.5^{\star}$ & 18 & $51.4^{*}$ & $<0.001$ \\
\hline Fetals & 14 & 12.2 & 15 & $46.8^{*}$ & 11 & $37.9 *$ & 15 & $42.8^{*}$ & $<0.001$ \\
\hline Obstetrical & 94 & 81.0 & 11 & 34.5 & 08 & 27.6 & 02 & 5.8 & ns \\
\hline
\end{tabular}

Most cases of mild preeclampsia develop near term and have mortality and perinatal morbidity rate similar to those of normotensive pregnant women, or as later it manifests fewer complications may be caused. It is known that the complications of gestational hypertension are preventable with the expansion of prenatal coverage, preparation of qualified professionals, early diagnosis of high-risk pregnancy and an effective and quick reference system for secondary or tertiary care centers as access to the Intensive Care Unit, preferably obstetrical units [2].

Lucyk and Furumoto (2008) emphasize that pregnant women are a group with many peculiarities in the composition of their diet, and that if this is not followed strictly, some conditions that are not favorable may harm both the mother to the fetus, among pathological maternal nutritional status inadequate, are the hypertensive disorder in pregnancy and gestational diabetes [21]. Table 2
The table above provides results that help us understand and compare with other studies showing the risk factors for developing PE, and analyzing it setbacks could be found and questioning some results with other studies in the literature. The first setback can be observed in the number of times a woman has already become pregnant. In the study of Assis, Viana, Rassi (2008) it is shown that the variables that were risk factors for $\mathrm{GH}$ were primiparity, as well as for PE were nonwhite race.

However Coelho et. al. (2004) found other information about the number of pregnancies and this suggests that the number of participants of the interview, the location and quality of care provided for pregnant women can influence the results, so it is still necessary better researches and more studies to clarify the real causes of the appearance of PE.

Early diagnosis of hypertension becomes an ally of the team accompanying the pregnant woman, but it is not always possible to perform the diag- 
nosis, because it is necessary a rigorous prenatal care, which is often far from the reality of many patients. There are two explanations for these results: one is that pregnant women developed later hypertension, and the other is that this diagnosis was delayed because of the care provided, and this puts the mother and fetus at risk.

Lifestyle habits can also be seen as a risk factor for the development of hypertension, since an external situation such as stress may ultimately exacerbate pregnancy, being this considered an extrinsic factor, as overweight can also complicate. In this situation one has to work in an attempt to reduce this anxiety and/or distress, and investigate how feeding is going on and refer to a specific professional to nutritional education, respectively.

Santana (2010), emphasizes the statement that hypertension develops from the genetic component, environmental, cultural and behavioral factors such as lifestyle and poor eating habits, as well as this increase in blood pressure may be associated with age, ethnicity, socioeconomic status, alcohol intake, exacerbated intake, stress, diabetes, obesity and physical inactivity [2].

\section{Nursing care provided to pregnant women with PE}

Preeclampsia can be prevented with proper obstetric care and sensible resolution of pregnancy, since it is a prevalent disease in the low socioeconomic status population, changing maternal mortality with the quality of access to health care. For not having the certain methods to identify cases that should develop into Eclampsia, seizure prophylaxis in severe preeclampsia or BP values greater than 160×105 $\mathrm{mm} \mathrm{Hg}$ is recommended. Studies show that the use of magnesium sulfate in pregnant or postpartum women with PE and no imminent eclampsia signs proved to be effective in reducing by half the risk of seizures [1].

It is true that hypertension can reach a more serious condition: preeclampsia, the most serious among the hypertensive disorders, and if not diagnosed early and treated, it is a potentially devastating disease, so these two actions are the most important interventions, as well as recognize its risk factors in an attempt to prevent progression to the most serious stage: eclampsia, and later evolve into other more serious syndrome that causes decompensation of all body systems, especially in coagulation, leading to ICU admissions and even death [22].

Prematurity of birth is indicated for prevention the natural evolution of the disease, because when untreated or pregnancy is not interrupted, it can trigger these severe forms, including seizures (Eclampsia) [1].

The Preeclampsia does not stand out only as the most serious complication of pregnancy period, but also stands out as the main concern of pregnant women and professionals who accompany them, as evidenced Martins et. al (2012), the fear of complications attributed by women, among them the fear of death (hers and the baby) [23]. Fear was the most common sentiment revealed by pregnant women with hypertension in many works already produced following this theme. This feeling is divergent, not having the same meaning for all of them, but fear can be a negative result in the form of transmitting information in prenatal consultations.

Thus, there were several findings in the literature, whereas the hypertensive pregnant women should undergo the caesarean section, because an increased security is guaranteed to her, since it is allowed to plan health actions that will be performed. Cabral, Costa and Cabral Junior (2003), reinforce saying that the caesarean section indications before were practically restricted to mechanical dystocia, but they were extended and Hypertensive Disorders in Pregnancy got into the category of priority, and this should be explained during the pre natal to reassure and prepare the mother for surgery [24].

All actions performed require involvement, commitment and humanization by the professionals involved, as they are committed to exchange experien- 
ces and knowledge in the care of pregnant women will not be an easy process, where the particularity of each one must be observed, as the Preeclampsia situation is similar, but the causes are different, and this should encourage the health team to develop actions to streamline care and avoid complications [25-27].

\section{Conclusion}

Regarding the theme, this study sought to understand the risk factors that lead pregnant women develop preeclampsia and health actions collaborate for a good outcome of pregnancy, as the Health Units, both Basic and Reference has duty to prepare individualized and qualified assistance strategies to the public concerned.

Studies reveal that the experiences of these women who are affected by any of the HDP are marked by negative feelings; especially fear related to complications and death, both the baby as their own. It is also realized that in some cases the situations are enhanced by the environment in which the pregnant woman is inserted, which helps to generate stress and exposing them to the difficulty of caring.

All questions related to the evolution of pregnancy and some postpartum care should be clarified by the pregnant woman team that provides care. As the most suitable type of delivery has to be discussed and explained, pointing out why that preference will be given to cesarean section, and what possible complications can happen, but always showing the positive side, as this communication failure directly affects the pregnant hospitalization.

The history and physical examination are individual actions to be undertaken in the search for abnormalities in the development of pregnancy, and when well applied it serves as an important tool in the control and minimization of complications, however when the service is not well planned, instead of helping it ends aggravating the health status of the patient, as the mother will be even more apprehensive and insecure with the evolution of pregnancy.

In this sense, it is important that the professional team members are involved in the changes, and the environment should be cozy and quiet, and professionals should take consciously commitment to pregnant women in caregiver status and health facilitator, contributing to the socialization of knowledge with the adoption of care practices in the art of caring.

Through the above data in the survey, it was noted that there is a failure in that disrespects the humanized and educational consultation, being these of utmost importance to improve the care provided to pregnant women, where professionals can see the interactive, complementary and multi need. In this perspective, it is worth noting that the training of professionals is a current requirement, so they can succeed in the implementation of this new assistance, and consequently achieving positive results against the pregnant woman's prognosis.

It is remarkable that prenatal consultations have shown a decrease in maternal and perinatal morbidity and mortality rates, however there is still much to be reviewed, such as how to accommodate this public, and even the Ministry of Health advocating the humane care, much see a mechanized service and minimum demonstrations of concern for the pregnant woman and the fetus, and pregnant women are lay with regard to Preeclampsia.

\section{References}

1. Peraçoli JC, Parpinelli MA. Síndromes hipertensivas da gestação: identificação de casos graves. Revista Brasileira de Ginecologia e Obstetrícia, São Paulo, v.27, n.10, p.627-634, 2005.

2. Santana FSN, Silva GAP, Malacarne RR, Toledo Neto JL, Popolin MP, Marzola C. Atuação da enfermagem em urgênciasGestação de alto risco- Hipertensão arterial, p.653-673, 2010.

3. Assis TR, Viana FP, Rassi S. Estudo dos Principais Fatores de Risco Maternos nas Síndromes Hipertensivas da Gestação. Sociedade Brasileira de Cardiologista, v.91, n. 1, p.11-17, 2008. 
4. Gonçalves R, Fernandes RAQ, Sobral DH. Prevalência da Doença Hipertensiva Específica da Gestação em hospital público de São Paulo. Revista Brasileira de Enfermagem, v.58, n.1, p.61-64, 2005.

5. SBC-Sociedade Brasileira de Cardiologia. VI Diretrizes Brasileiras de Hipertensão, Rio de Janeiro, v.95, n.1, p.1-51, 2010.

6. Peixoto MV, Martinez MD , Valle NSB. Síndromes hipertensivas na gestação: estratégia e Cuidados de enfermagem. Revista de Educação, Meio Ambiente e Saúde, v.3, n.1, p.208-222, 2008.

7. Pascoal IF Hipertensão e gravidez. Revista Brasileira de Hipertensão, v.9, n.3, p.256-261, 2002.

8. Souza AR, Amorim MR, Costa AAR, Noronha Neto C. Tratamento anti-hipertensivo na gravidez. Acta Médico Portuguesa., v.23, n.1, p.77-84, 2010

9. Siqueira F, Moura TR, Silva SS, Eraçoli JC. Medicamentos antihipertensivos na gestação e puerpério. Comitê de Ciências Saúde, v.22, n.1, p.55-68, 2011.

10. Reiners AAO, Dióz M, Teixeira NZF, Gonçalves PMS. Diagnósticos de enfermagem em gestantes hipertensas. Revista Mineira de Enfermagem-REME, v.13, n.2, p.232-237, 2009.

11. Aguiar MIF, Freire PBG, Cruz IMP, Linard AG, Chaves ES, Rolim. Sistematização da assistência de enfermagem a paciente com síndrome hipertensiva específica da gestação. Revista Rene. Fortaleza, v.11, n.4, p.66-75, 2010.

12. Marques, C. L.; Cunha, L. R.; Rehbein, F.; SILVA, M. L. S.. Doença Hipertensiva Específica da Gestação em uma Unidade Básica de Saúde de Pelotas. Congresso de Iniciação Científica. Universidade Federal de Pernambuco, 2011.

13. Mendes KDS, Silveira RCCP, Galvão CM. Revisão integrativa: método de pesquisa para a incorporação de evidências na saúde e na enfermagem. Texto contexto - enferm., Florianópolis, v.17, n.4, p.758-764, 2008.

14. Dalfovo MS, Lana RA, Silveira A. Métodos quantitativos e qualitativos: um resgate teórico. Revista Interdisciplinar Científica Aplicada, v.2, n.4, p.1-13, 2008.

15. Leopardi MT . Metodologia da Pesquisa na Saúde. $2^{a}$ Ed., Florianópolis: NFR/UFSC- Pós-Graduação de Enfermagem, 2002.

16. Gomes AG, Donelli TMS, Piccinini CA, Lopes RCS. Maternidade em Idade Avançada: Aspectos Teóricos e Empíricos. Interação em Psicologia, v.12, n.1, p. 99-106, 2008

17. Moura ERF, Oliveira CGS, Damasceno AKC, Pereira MMQ. Fatores de risco para síndrome hipertensiva específica da gestação entre mulheres hospitalizadas com pré-eclâmpsia. Cogitare Enfermagem, v.15, n.2, p.250-255, 2010

18. Vettore MV, Dias M, Domingues RMS, Vettore MV, Leal MC. Cuidados pré-natais e avaliação do manejo da hipertensão arterial em gestantes do SUS no Município do Rio de Janeiro, Brasil. Caderno de Saúde Pública, v.27, n.5, p.1021-1034, 2011.

19. Sampaio TAF, Santana TD, Hanzelmann RS, Santos LFM, Montenegro HRA, Martins JAA, Helena AAS, Ferreira DC. Cuidados de enfermagem prestados a mulheres com hipertensão gestacional e pré-eclâmpsia. Revista de Saúde Física \& MentalUNIABEU, v.2 n.1, p.36-45, 2013.
20. Angonesi J, Polato A. Doença Hipertensiva Específica da Gestação (DHEG), Incidência à Evolução para a Síndrome de HELLP. Revista Brasileira de Análises Clínicas, v.39, n.4, p. 243245, 2007.

21. Lucyk JM, Furumoto RV. Necessidades nutricionais e consumo alimentar na gestação: uma revisão. Comitê Ciências Saúde, v.19, n.4, p.353-363, 2008.

22. Melo BCP, Amorim MMR, Katz L, Coutinho I, Veríssimo G. Perfil epidemiológico e evolução clínica pós-parto na pré-eclâmpsia grave. Revista de Medicina Brasileira, v.55, n.2, p.175-180, 2009.

23. Martins M, Monticelli M, BrÜggemann OM, Costa R. A produção de conhecimento sobre hipertensão gestacional na pós-graduação stricto sensu da enfermagem brasileira. Revista da Escola de Enfermagem USP, v.46, n.4, p.802-808, 2012.

24. Cabral SAL, Costa CFF, Cabral Júnior SF. Correlação entre a idade materna, paridade, gemelaridade, síndrome hipertensiva e ruptura prematura de membranas e a indicação de parto cesáreo. Revista Brasileira de Ginecologia e Obstetrícia, v.25, n.10, p.739-744, 2003

25. Amorim $M M R$, Katz $L$, Ávila $M B$, Araújo $D E$, Valença $M$, Albuquerque CJM, Carvalho ARMR, Souza ASR. Perfil das admissões em uma unidade de terapia intensiva obstétrica de uma maternidade brasileira, Revista Brasileira de Saúde Materna e Infantil, v.6, 2006.

26. BRASIL. Ministério da Saúde. Secretaria de Atenção à Saúde. Departamento de Ações Programáticas Estratégicas. Estratégias para o cuidado da pessoa com doença crônica: hipertensão arterial sistêmica. Brasília: Ministério da Saúde, 2013.

27. Coelho TM, Martins MG, Viana E, Mesquita MRS, Camano L, Sass N. Proteinúria nas síndromes hipertensivas da gestação: Prognóstico materno e perinatal. Revista da Associação Médica Brasileira, v.50, n.2, p.207-213, 2004.

Publish in International Archives of Medicine

International Archives of Medicine is an open access journal publishing articles encompassing all aspects of medical science and clinical practice. IAM is considered a megajournal with independent sections on all areas of medicine. IAM is a really international journal with authors and board members from all around the world. The journal is widely indexed and classified Q1 in category Medicine. 